\title{
Trends and sources identification of non-methane hydrocarbons (NMHC) concentration in rural areas in France
}

\author{
S. Sauvage, H. Plaisance, N. Locoge, P. Coddeville \& J. C. Galloo \\ Ecole des Mines de Douai, Environmental and Chemistry Department, \\ Douai, France
}

\begin{abstract}
Investigations on long term trends of non-methane hydrocarbons (NMHCs) in rural areas are of interest for a better understanding of tropospheric ozone concentration. NMHC were measured on a French rural site from 2002 to 2005, as part of the EMEP program. First, the examination of the levels and trends showed a global decrease in NMHCs. These results are in accordance with the levels observed in other sites in Europe. They are also in agreement with the decrease of NMHC emissions in France as positive consequences of the European directive 99/13/CE. Nevertheless, we note a pronounced increase in biogenic compounds like isoprene, one species having a high potential of ozone formation. Secondly, data handling was based on receptor modelling using Positive Matrix Factorization (PMF) to characterize NMHC source profiles and their contributions. Six main profiles have been identified: domestic heating (28.2\%); remote sources $(22.1 \%)$, solvent use $(18.4 \%)$, vehicle exhaust $(10.6 \%)$, gasoline evaporation $(9.9 \%)$ and biogenic $(7.1 \%)$. This work is completed by a clustering analysis of air trajectories in order to apportion local and regional source contributions to the measured concentrations on the sampling site. The final aim of this study is to carry out a NMHC data extensive analysis in order to improve the comprehension of the increase trend of background ozone. Keywords: NMHC, rural atmosphere, trajectory analysis, receptor model, PMF, source apportionment.
\end{abstract}




\section{Introduction}

It has been well established that non methane hydrocarbons (NMHC) play an important role as precursors to ozone and other secondary photochemical pollutants. Ozone exceedences continue to be a major problem, especially at rural location in Europe where a large fraction (10-40\%) of the population, was exposed to ground-level ozone concentrations above the health-protection-based target level [14]. For that reason, the relationship between ozone and its precursors still remains an issue of important concern. The distribution of NMHC is the result of three major combined processes: (1) primary and secondary formation process, (2) removal process and (3) mixing process.

(1) Sources and primary NMHC are both of anthropogenic and biogenic origin. Major anthropogenic sources are related to fossil fuel combustion (vehicle exhaust, heat generation, combustion in industries), storage and distribution of fuel (evaporation) and solvent use [7].

(2) Mechanisms of NMHC oxidations are mainly induced by the hydroxyl radical $\mathrm{OH}$ in daytime, by the $\mathrm{NO}_{3}$ at night, and ozonolysis for unsatured compounds [1].

(3) Mixing process, closely related to meteorological conditions within the mixing boundary layer, tend to redistribute the pollutants through advective and convective transport at a regional or long-range scale, especially for long life time species (ethane, propane).

The consideration of the relative importance of these factors can provide relevant information for a better understanding on NMHC impact on tropospheric chemistry. The objective of this work is to assess and apportion sources of rural NMHC on a temporal basis. To do so, a receptor model approach was used to analyse data of one rural site in France.

\section{Sampling site and measurement methods}

\subsection{Sites description}

Data sets $(\mathrm{N}=390$, completeness $=93.5 \%)$ used in this study correspond to samples collected at one of the three rural EMEP sites of Tardière belonging to the French rural monitoring network called MERA (MEsure des Retombées Atmosphériques). The site (Figure 1) is located $1 \mathrm{~km}$ in the north of a small urban area (3,000 ha) and $50 \mathrm{~km}$ away from the sea. The most polluted area is located $100 \mathrm{~km}$ in the northeast of the site with a big urban centre (Nantes 270,000 ha.) and a petroleum refining plant.

\subsection{NMHC sampling and analysis}

Measurements have been performed since 2002. Sampling is carried out twice a week on Tuesdays and Thursdays around 12:00 UT for 4 hours.

Stainless steel canisters (6L) provide the collection of NMHC samples according to the well-established TO-14 method [21] for many none polar VOC, 
so used in the EMEP network. NMHC sampling has been done with canister sampler from Andersen instruments Inc. NMHC analysis is carried out by a VOC analyser (VOCAA from Chrompack equipped by an auto TCT/CP9000GC). Separation is performed by a dual capillary column system equipped with a switching device. The analytical conditions were described by Locoge and Galloo [16]. Four main steps constitute the QA/QC programme which is based on the TO-14 method (1997): (1) the establishment of standard operating procedures, (2) canister cleaning and certification $(<0.02 \mathrm{ppbv})$, (3) sampling system cleaning and lab certification, (4) in-situ tests with collocated samplers in field.

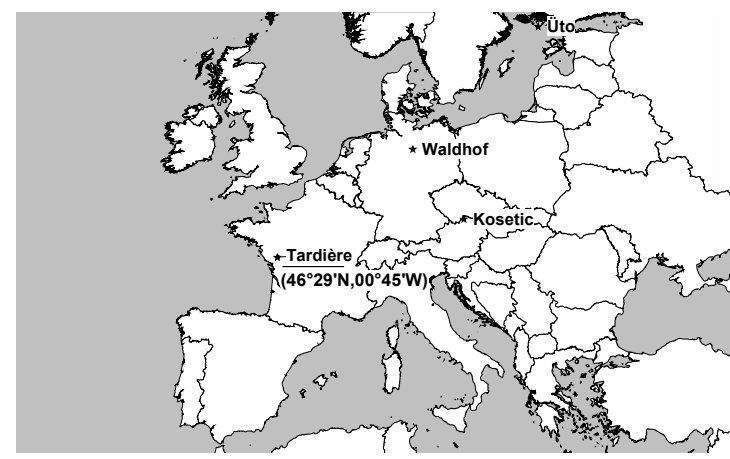

Figure 1: The Tardière sampling site and other EMEP sites.

\section{Levels and trends}

The annual average concentrations reported in table 1 are in good agreement with those observed in the other EMEP sites (http://www.nilu.no/projects/ccc/emepdata). That confirms the rural typology of this site. Besides, French site denotes by its higher concentrations in isoprene due to its climatology and the density of its vegetation.

Table 1: Comparison with other EMEP sites located in Figure 1 (Annual average in $\mathrm{ppb}$ ).

\begin{tabular}{ccccccccccccc}
\hline & \multicolumn{4}{c}{ Ethane } & \multicolumn{4}{c}{ Acetylene } & \multicolumn{5}{c}{ Isoprene } \\
Site & 2002 & 2003 & 2004 & 2005 & 2002 & 2003 & 2004 & 2005 & 2002 & 2003 & 2004 & 2005 \\
\hline Tardière (France) & 1.794 & 1.864 & 1.785 & 1.732 & 0.446 & 0.546 & 0.477 & 0.439 & 0.119 & 0.190 & 0.150 & 0.157 \\
Üto (Finland) & 1.692 & 2.012 & 1.611 & & 0.336 & 0.449 & 0.362 & & 0.017 & & & \\
Waldhof (Germany) & 1.784 & 1.824 & 1.760 & & 0.707 & 0.824 & 0.789 & & 0.031 & 0.033 & 0.04 \\
Kosetic (Czech Republic) & 2.189 & 1.994 & 1.641 & & 1.136 & 0.97 & 0.819 & & 0.041 & 0.047 & 0.026 \\
\hline
\end{tabular}

As already observed in rural and remote sites [9, 20], NMHC exhibit pronounced seasonal cycles (Figure 2). The cycle of anthropogenic compounds (e.g. ethane, acetylene and benzene) shows maxima in winter which reflects emission strengthening in that period, for instance with heating function and 
vehicle "cold start" effect. In addition, chemical lifetimes of hydrocarbons are prolonged due to the low concentration of $\mathrm{OH}$ and the weaker UV-radiation compared to in summer. Furthermore, the height of the mixed boundary layer is often lower in winter than in summer. Moreover, summer minima highlights photochemical process. For $\mathrm{C}_{2}-\mathrm{C}_{4}$ alkanes, ground levels persist due to their long atmospheric residence time (several days). For short lived species (few hours), concentrations in summer are sometimes close to the Detection Limits (DL). Isoprene shows a clear opposite cycle indicating the contribution of biogenic emissions in summer. Some very high values occurring in summer for this species are well correlated with high levels of ambient temperature.

Times series (Figure 2) shows systematically some extreme valid values in winter for ethane, acetylene and benzene. Nevertheless, observed concentrations are lower than those observed in urban area. High concentrations of acetylene and benzene are correlated with high levels of short lived species like ethylene or propylene. So these events can be due to combustion emissions (vehicle exhaust or domestic heating) closer to the site. For Ethane, the trajectory analysis confirms that air masses associated with very high values of concentration have passed over urban areas. In the following section, we have considered the sensibility of the model to the extreme values.

Time series (Figure 2) for anthropogenic species have shown decreasing trends especially for benzene in relation to its volume limitation in fuel since 1999 (directive 98/70/EC).
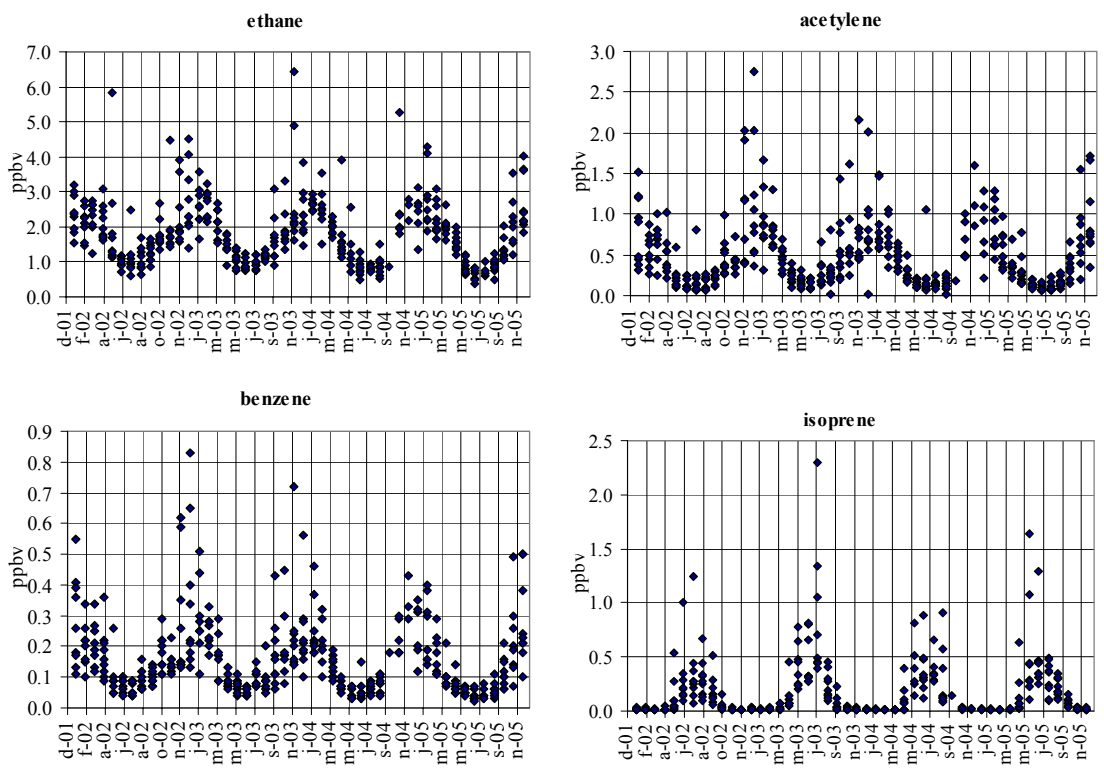

Figure 2: Typical NMHC Time series at Tardière site. 


\section{Methods}

\subsection{PMF model}

The PMF was described by Paatero and Tapper [18] and has been used in many source identification studies involving VOC measurements in ambient air [2, 15, 23]. The PMF2 program and additional guidance on the use of PMF [13] were used for this study. The PMF2 solve the receptor modelling:

$$
\mathrm{x}_{\mathrm{ij}}=\sum_{\mathrm{k}=1}^{\mathrm{p}} \mathrm{g}_{\mathrm{ik}} \mathrm{f}_{\mathrm{kj}}+\mathrm{e}_{\mathrm{ij}}
$$

where $x_{\mathrm{ij}}$ is the $j$ th species concentration measured in the $i$ th sample, $g_{i k}$ is the contribution of the $k$ th source to the $i$ th sample, $f_{k j}$ is the $j$ th species mass fraction form the $k$ th source, $\mathrm{p}$ is the number of independent sources, and $e_{i j}$ is the residual associated with the concentration of the $j$ th species in the $i$ th sample.

The PMF2 program minimizes the residual sum of squares, Q, given by:

$$
\mathrm{Q}=\sum_{\mathrm{i}=1}^{\mathrm{n}} \sum_{\mathrm{j}=1}^{\mathrm{m}} \frac{\mathrm{e}_{\mathrm{ij}}^{2}}{\mathrm{~s}_{\mathrm{ij}}^{2}}=\sum_{\mathrm{i}=1}^{\mathrm{n}} \sum_{\mathrm{j}=1}^{\mathrm{m}}\left(\frac{\mathrm{x}_{\mathrm{ij}}-\sum_{\mathrm{k}=1}^{\mathrm{p}} \mathrm{g}_{\mathrm{ik}} \mathrm{f}_{\mathrm{kj}}}{\mathrm{s}_{\mathrm{ij}}}\right)^{2} \quad f k j \geq 0 \text { and } g_{i k} \geq 0
$$

where $s_{i j}$ is an uncertainty estimate for the $j$ th species measured in the $i$ th sample according to equation:

$$
\mathrm{s}_{\mathrm{ij}}=\sqrt{\left(\mathrm{DL}_{\mathrm{i}} / 3\right)^{2}+\left(0,1 \cdot \mathrm{x}_{\mathrm{ij}}\right)^{2}}
$$

$D L_{\mathrm{i}}$ is the detection limit of the analytical method for the $i$ th species. Values below the DL were replaced by half of the DL and 5/6 of DL was assigned as their associated uncertainties [13]. Missing values were replaced by the geometric mean of the measured values, and associated uncertainties were set at four times this geometric mean. Various runs were done in order to optimise the selection of parameters and to test the robustness of PMF model.

Finally, the results were scaled to the measured concentration using a scaling constant, $s_{k}$, obtained by regression from the measured NMHC concentrations against the source contributions, $g_{i k}$ :

$$
\mathrm{x}_{\mathrm{ij}}=\sum_{\mathrm{k}=1}^{\mathrm{p}}\left(\mathrm{s}_{\mathrm{k}} \mathrm{g}_{\mathrm{ik}}\right)\left(\frac{\mathrm{f}_{\mathrm{kj}}}{\mathrm{s}_{\mathrm{k}}}\right)
$$

The number of factors was determined such as (1) additional factors did not improve the $Q$ values significantly, (2) the residual values have a symmetric distribution and were within \pm 2 , (3) scaling constants $s_{k}$ from regression were all positive.

The PMF factors were then explained by comparing them with known emission profiles. 


\subsection{Trajectory analysis}

Many studies have demonstrated the influence of atmospheric transport patterns on pollutants concentration by considering air mass trajectories [5,3,4]. Each sample was associated with its 5-day 3-hourly 3D-back trajectories arriving at the sampling station at 12:00 GMT $(\mathrm{P}=950 \mathrm{hPa})$. These trajectories were calculated by the British Air Data Centre. K-means clustering algorithm is used to group these trajectories depending on their direction, their speed and their altitude. The aim of this technique is to maximise between-group variance and to minimize within group variance. The method of determining the number of clusters to retain is the same as the one reported in Dorling et al [5].

\section{Results and discussion}

47 of the 55 measured species were used for PMF analysis. Those with less than $20 \%$ of their values above the DL were not considered. Eight factors (reported in Figure 3) were retained for PMF analysis. Good mass reproduction was obtained with this set of factors $\left(R^{2}=0.97\right)$. Seven of the eight factors have been correctly identified.

The first factor F1 is dominated by ethane, propane, acetylene, butane, benzene and ethylene. Contribution time series shows a marked cycle with maxima in winter. Taking into account the lower urban density (limitation of the number of sources influencing the site), the average winter temperature $\left(8.5^{\circ} \mathrm{C}\right)$ and by comparison with emission profiles resulting from GEMENIS database [8], F1 was identified as domestic heating function. This factor represents the highest contribution (28.2\%).

Ethane is the predominant compound for factor F6. Because of its low reactivity, it is commonly associated to the contribution of old air masses brought by air transport towards the sampling site or closer sources like natural gas leak. That is the reason why this profile is usually labelled "remote sources" [11.2]. This source shows a significant contribution (22.1\%).

Toluene, mp-xylene, o-xylene and ethylbenzene characterize the factor F8 (18.4\%). These aromatic compounds are emitted mainly from industrial solvent use sources [10]. The time series since 2002 to 2005 has shown a significant decrease of its contribution.

Ethylene and acetylene are the main components of F2 and F7. These species can be considered as profile of industrial sources or profile of automobile exhaust. Considering the short lifetime of ethylene, and the rural typology of the site without close industrial plant, these factors are associated with vehicle exhaust. The profile of automobile exhaust [6] corroborates this identification. The examination of contributions time series shows that F2 and F7 concern this profile respectively in winter and in summer. These factors represents $10.6 \%$ of the total contribution.

The factors F5 are abundant with propane, ethane associated with butane, isobutane, pentane, iso-pentane, benzene and toluene. This association seems to correspond to evaporative sources like gasoline vapour that usually do not 
consist of the combustion compounds or from heavier hydrocarbons that volatilize more slowly [22]. F5 represents a contribution of $9.9 \%$.
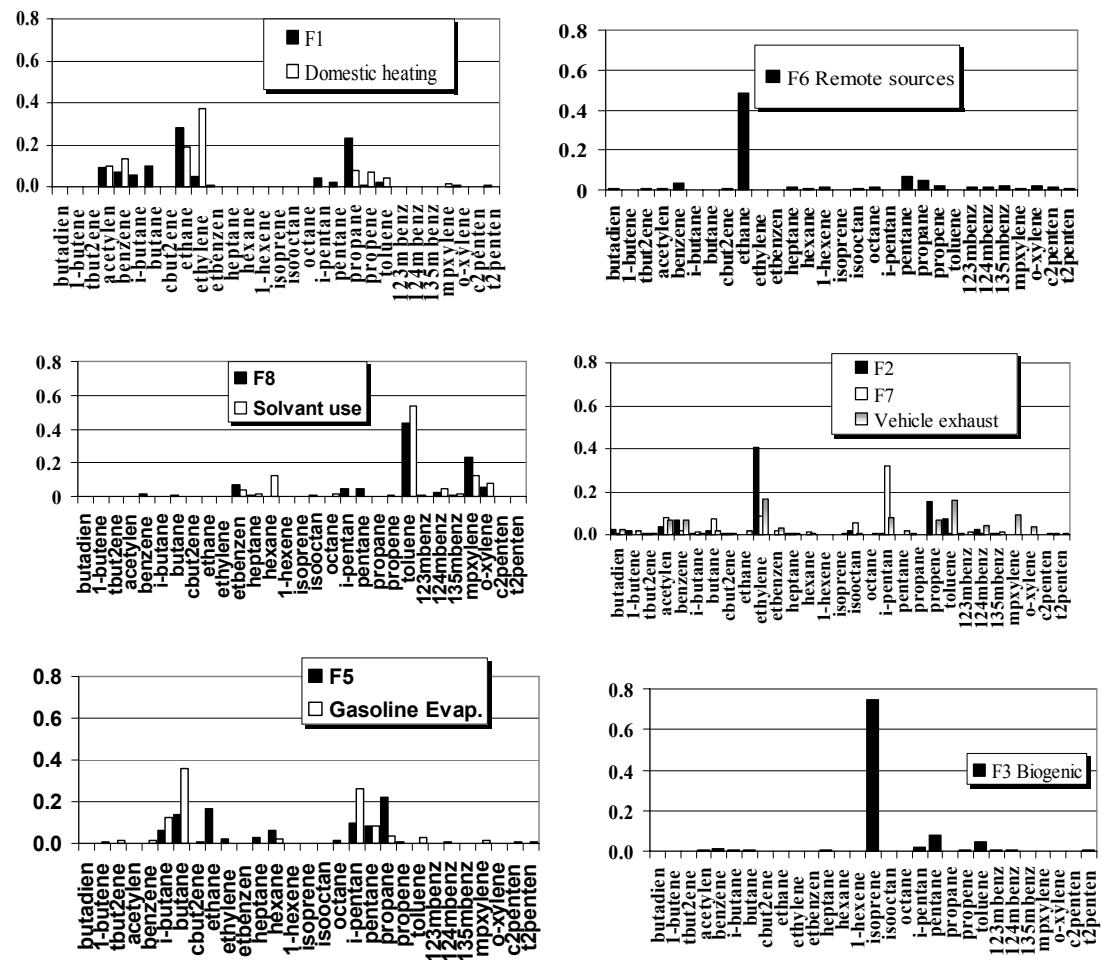

Figure 3: $\quad$ PMF Source factors in comparison with known source profiles.

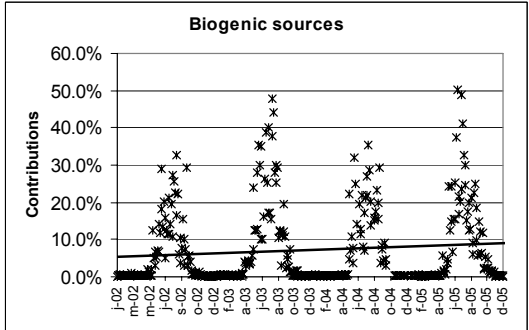

Figure 4: $\quad$ Time series of contribution for biogenic sources

Factor F3 is labelled biogenic emission with isoprene as a predominant compound. Biogenic VOC emissions from vegetation are characterized by isoprene, which is commonly used as the marker of biogenic emissions. This compound is significantly higher in summer (Figure 4) and is well correlated with temperature. A possible contribution of industrial or automobile sources can here be neglected. Moreover, as observed in Figure 4, this moderate 
contribution $(7.1 \%)$ tends to increase which became a particular concern because of the important role of isoprene in ozone formation.

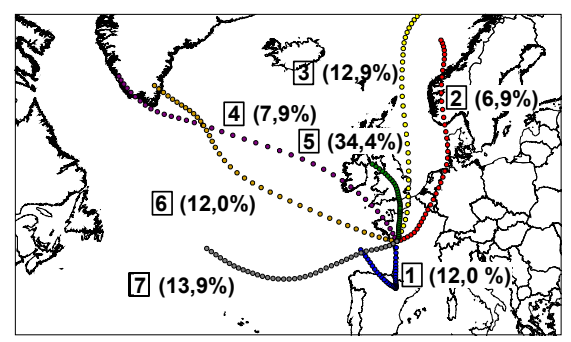

Figure 5: Average trajectories obtained by clustering analysis-relative share (\%) of clusters.

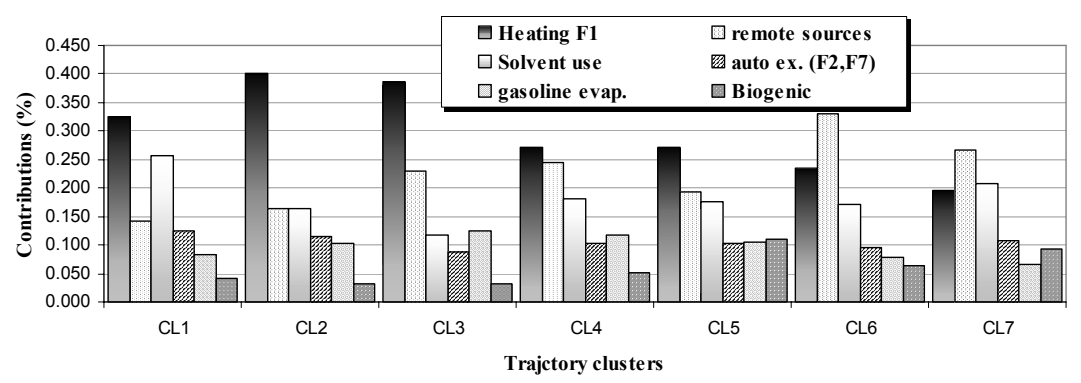

Figure 6: $\quad$ Source contributions.

The average trajectories and the representativeness of the seven clusters obtained are reported in Figure 5. The contributions of factors are reported in Figure 6 for each trajectory cluster. For five by seven clusters, the factor F1 related to heating source remains the principal component. We distinguish one group of clusters (continental clusters 1, 2, 3 and 4) more influenced by local emissions like domestic heating, solvent use or gasoline evaporation exhaust. Besides, Oceanic clusters 6 and 7 are less influenced by nearest urban sources. This group is dominated by the contribution associated with remote sources factor. Cluster 5 is mainly represented in summer. Highest contributions in biogenic sources appear in this cluster in comparison with others.

\section{Conclusion}

Concentration data of $55 \mathrm{NMHC}$ were measured on a rural site belonging EMEP network. The examination of time series underlines a significant decrease for anthropic compounds especially for Aromatics as positive consequence of European directives. Furthermore, concentrations in isoprene are typically high in France with a significant increasing temporal trend, which is becoming a particular concern due to the important role of isoprene in ozone formation. 
Secondly, data handling was analysed by Positive Matrix Factorization PMF to characterize source profiles and to compare their relative importance in rural areas. Six main profiles have been identified: domestic heating $(28.2 \%)$; remote sources $(22.1 \%)$, solvent use $(18.4 \%)$, vehicle exhaust $(10.6 \%)$, gasoline evaporation $(9.9 \%)$ and biogenic $(7.1 \%)$. Resulting from trajectory clustering analysis, the source contributions were shared into two main groups: (1) oceanic characterized by older air masses and (2) continental more influenced by local emissions. In a future work, a backward trajectory method will be applied to source contributions deduced from PMF in order to locate source regions.

\section{References}

[1] Atkinson, R. (1994). Gaz phase tropospheric chemistry of organic compounds. Monographie $\mathrm{n}^{\circ} 2$, American Chemical Society and the American Institute of Physics, 216p.

[2] Buzcu B., Fraser M.P. (2006), Source identification and apportionment of volatile organic compounds in Houston, TX. Atmos. Environ. 40, $2385-$ 2400.

[3] Cape J.N., Methven J., Hudson L.E. (2000), The use of trajectory cluster analysis to interpret trace gas measurements at Mace Head, Ireland. Atmos. Environ. 34, 3651-3663.

[4] Diaz A.M.; Diaz J.P., Exposito F.J., Hernandez-Leal P.A., Savoie D., Querol X., (2006). Air masses and aerosols chemical components in the free troposphere at the subtropical northeast Atlantic region. Journal of Atmospheric Chemistry, 53, 63-90.

[5] Dorling S.R., Davie T.D., Pierce C.E. (1992a) Cluster analysis : A technique for estimating the synoptic meteorological controls on air and precipitation chemistry - Method and applications. Atmos. Environ. 26(A), 2575-2591.

[6] Fontaine H., (2000), Les Composés Organiques Volatils dans les gaz d'échappement des automobiles: Etablissement de profils d'émissions représentatifs des différentes conditions de conduite, thèse de doctorat présentée à l'Université de Technologies de Compiègne.

[7] Friedrich R., Obermeier A., (1999) Anthropogenic emissions of volatile organic compounds. In: Hewitt, N.C. (Ed.), Reactive Hydrocarbons in the atmosphere. Academic press, San Diego, USA, 1-39.

[8] GENEMIS, Base de données, Institute for Energy Economics and Rational Use of Energy, Université de Stuttgart, disponible sur http:/genemis.ier.uni-stuttgart.de/

[9] Hagerman L.M., Aneja V.P., Lonneman W.A., (1997), Characterization of non-methane hydrocarbons in the rural southeast United States. Atmos Environ. 31, 4017-4038.

[10] Harley R. A., Hannigan M. P., Cass G. R., (1992), Respeciation of organic gas emissions and the detection of excess unburned gasoline in the atmosphere, Environmental Science and Technology, 26, 2395-2408.

[11] Hellén H., Hakola H., Laurila T., (2003), Determination of source contributions of NMHCS in Helsinki $\left(60^{\circ} \mathrm{N}, 25^{\circ} \mathrm{E}\right)$ using chemical mass 
balance and the UNMIX multivariate receptor models, Atmospheric Environment, 37(11), 1413-1424.

[12] Hellén H., Hakola H., Pirjola L., Laurila T., Pystynen K.-H., (2006), Ambient Air Concentrations, Source Profiles, and Source Apportionment of 71 Different C2-C10 Volatile Organic Compounds in Urban and Residential Areas of Finland, Environmental Science and Technology, 40(1), 103-108.

[13] Hopke P.K. (2000) a guide to positive matrix factorization. EPA Workshop Proceedings Materials from the Workshop on UNMIX and PMF applied to PM2,5.

[14] Larssen S., Barrett K.J., Fiala J., Goodwin J., Hagen L.O., Henriksen J.F., De Leeuw F., Tarrason L., (2002) Air quality in Europe: state and trends 1990-1999. Topics report, April 2002, European Environment Agency, Copenhagen, Denmark.

[15] Latella A., Stani G., Cobelli L., Duane M., Junninen H., Astorga C., Larsen B. R., (2005), Semicontinuous GC analysis and receptor modelling for source apportionment of ozone precursor hydrocarbons in Bresso, Milan, 2003, Journal of Chromatography A, 1071(1-2), 29-39.

[16] Locoge N, Galloo J.C., (1998), Analysis of VOC in rural sites. MERA final report. June 1998, Department of chemistry and Environment, Ecole des Mines de Douai, France, 145-173.

[17] Miller S.L., Anderson M.J., Daly E.P., Milford J.B., (2002), Source apportionment of exposures to volatile organic compounds. I. Evaluation of receptor models using simulated exposure data, Atmospheric Environment, 36(22), 3629-3641.

[18] Paatero P., Tapper U., (1994), Positive matrix factorization: a nonnegative factor model with optimal utilization of error estimates of data values, Environmetrics, 5, 111-126.

[19] Sharma U.K., Kajii Y., Akimoto H., (2000), Seasonal variation of $\mathrm{C}_{2}-\mathrm{C}_{6}$ NMHCs at Happo, a remote site in Japan. Atmos. Environ. 34, 44474458.

[20] Solberg S., Dye C., Schimdbauer N., Herzog A., Gerhig R.,(1996), Carbonyls and non methane hydrocarbons at rural European sites from the Mediterranean to the Artic. J. Atmos. Chem. 25, 33-66.

[21] US EPA, (1997), Compendium method TO-14: determination of volatile organic compounds (VOCs) in ambient air using specially prepared canisters with subsequent analysis by gas chromatography. Second version, January 1997, EPA/625/R-96/010b, Cincinnati.

[22] Watson J.G., Chow J.C., Fujita E.M., (2001), Review of volatile organic compound source apportionment by chemical mass balance, Atmospheric Environment, 35(9), 1567-1584.

[23] Xie Y., Berkowist C.M., (2006) The use of positive matrix factorization with conditional probability functions in air quality studies: an application to hydrocarbon emissions in Houston, Texas. Atmos. Environ., 40, 30703091 . 